\title{
Anti-diabetic effect of Alpinia oxyphylla extract on 57BL/KsJ db-/db- mice
}

\author{
YIQIANG XIE ${ }^{1 *}$, MAN XIAO $^{2 *}$, DAN LI $^{2}$, HONGQIN LIU ${ }^{2}$, FENGLIN YUN ${ }^{2}$, \\ $\mathrm{YI} \mathrm{WEI}^{1}$, SHENGGANG SANG ${ }^{1}$ and GUANKUI DU ${ }^{2}$ \\ ${ }^{1}$ Hainan Medical College Affiliated Hospital; ${ }^{2}$ Department of Biochemistry and \\ Molecular Biology, Hainan Medical College, Haikou, Hainan 571199, P.R. China
}

Received December 21, 2015; Accepted December 23, 2016

DOI: $10.3892 / \mathrm{etm} .2017 .4152$

\begin{abstract}
Diabetes mellitus is characterized by high blood glucose levels. Increased levels of reactive oxygen species (ROS) may disrupt insulin signaling and result in insulin resistance. The Alpinia oxyphylla extract (AOE) possesses powerful antioxidant activity and may therefore inhibit the development of insulin resistance. The objective of the present study was to determine the effects of AOE on blood glucose, insulin and lipid levels in a type II diabetic nephropathy animal model (C57BIKsj db-/db-). All experiments were performed on male $\mathrm{C} 57 \mathrm{BL} / \mathrm{Ks} \mathrm{DB} / \mathrm{DB}$ and $\mathrm{db}$-/db- mice that were left to acclimatize for 1 week prior to the experimental period. AOE was administered to these mice at different dosages (100, 300 and $500 \mathrm{mg} / \mathrm{kg}$ ) for 8 weeks. The results demonstrated that AOE did not affect mouse weight, while blood glucose concentrations were found to significantly decrease in a dose-dependent manner $(\mathrm{P}<0.05)$. The effect of administering $500 \mathrm{mg} / \mathrm{kg}$ AOE (AOE500) to db-/db- mice was tested further. Treatment with AOE500 for 8 weeks led to improved glucose tolerance and reduced plasma insulin concentrations $(\mathrm{P}<0.05)$, as well as a significant decrease in triglyceride concentrations $(\mathrm{P}<0.05)$ and levels of total cholesterol $(\mathrm{P}<0.05)$ in $\mathrm{db}-/ \mathrm{db}-$ mice. Furthermore, treatment with AOE500 decreased the concentration of malondialdehyde, elevated the concentration of glutathione and increased the activities of the antioxidant
\end{abstract}

Correspondence to: Dr Guankui Du, Department of Biochemistry and Molecular Biology, Hainan Medical College, 3 Xueyuan Road, Haikou, Hainan 571199, P.R. China

E-mail: duguankui@163.com

*Contributed equally

Abbreviations: AOE, Alpinia oxyphylla extract; ROS, reactive oxygen species; PTEN, phosphatase and tensin homolog; OGTT, oral glucose tolerance test; TBARS, thiobarbituric acid reactive substance; MDA, malondialdehyde; SOD, superoxide dismutase; POD, peroxidase; BUN, blood urea nitrogen

Key words: Alpinia oxyphylla extract, oxidative stress, db-/dbmice, phosphatase and tensin homolog, hyperglycemia enzymes superoxide dismutase and peroxidase $(\mathrm{P}<0.05)$ in the livers of db-/db- mice. Meanwhile, AOE-treated mice exhibited significantly reduced urine albumin, creatinine and blood urea nitrogen excretion $(\mathrm{P}<0.05)$. In parallel, the upregulated expression of phosphatase and tensin homolog (PTEN) in the liver and kidneys of $\mathrm{db}-/ \mathrm{db}$ - mice was impaired following AOE500 treatment. The results of the present study suggest that $\mathrm{AOE}$ regulates blood glucose and lipid levels and improves renal function by mediating oxidative stress and PTEN expression at the onset of type II diabetes mellitus.

\section{Introduction}

Diabetes mellitus is a chronic metabolic disease caused by a disorder of insulin secretion that results in the development of insulin resistance in target tissues. This disease that causes complications, such as metabolic disorders and multiple organ damage syndrome, is becoming a major threat to human health, with $~ 350$ million cases in 2014 alone (1-3). Hyperglycemia is a major contributor to oxidative stress and reactive oxygen species (ROS) production $(4,5)$. Increased levels of ROS resulting from hyperglycemia may disrupt the insulin signaling cascade, stimulating the development of insulin resistance $(6,7)$. There has been a growing interest in dietary supplements and/or herbal medicines, which may improve the management of blood glucose due to their perceived safety and efficacy $(8,9)$. A number of plants have been found with potential anti-diabetic capacity, including Alpinia oxyphylla (10). This has been used in China for centuries as both a food and medicinal substance (11) and is widely used as a tonic, aphrodisiac and anti-polyuria according to the Chinese Pharmacopoeia (12). A. oxyphylla extracts (AOEs) are rich in polyphenols, polysaccharides, protocatechuic acid and labdane diterpene glycosides (13). These extracts possess potent antioxidant activity, which inhibit nitric oxide production and the biosynthesis of prostaglandin (14). Therefore, they have the potential to be developed as a therapeutic to treat diabetes mellitus.

Phosphatase and tensin homolog (PTEN), is a phosphoinositide phosphatase that negatively regulates the insulin signaling pathway. It has been demonstrated that inhibiting PTEN expression normalizes blood glucose concentrations and improves insulin tolerance in $\mathrm{db}-/ \mathrm{db}$ - mice (15). PTEN 
overexpression in 3T3-L1 adipocytes inhibited serine-threonine kinase protein kinase B (Akt) activation and glucose uptake. By contrast, reduced PTEN expression enhanced insulin-stimulated Akt and glycogen synthase kinase-3 $\alpha$ activity (16). These results suggest that PTEN may be a potential target to treat diabetes.

The primary objective of the present study was to determine the effects of AOE on blood glucose, insulin and lipid levels in a type II diabetic animal model, C57BIKsj db-/db-. The effects of administering 100,300 and $500 \mathrm{mg} / \mathrm{kg}$ of extract of A. oxyphylla to $\mathrm{db}-/ \mathrm{db}$ - mice were determined by measuring changes in the body weight and blood glucose concentrations in the mice. Furthermore, the effects of $500 \mathrm{mg} / \mathrm{kg}$ AOE on glucose tolerance, plasma insulin concentration, plasma lipid profiles, liver lipid profiles, albumin and osmotic diuresis were determined.

\section{Materials and methods}

Animals and treatment. All experiments were performed on 4-week old male C57BL/Ks DB/DB (normal mice, $12.6 \pm 1.8 \mathrm{~g}$ ) and $\mathrm{db}$-/db- mice (type II diabetic animal model, $17.8 \pm 1.9 \mathrm{~g}$ ). A total of 60 mice were purchased from the Model Animal Research Center of Nanjing University (MARC; Nanjing, China). Mice were left to acclimatize for 1 week prior to the experimental period. The room that animals were housed in was maintained under a constant 12-h light-dark cycle with a temperature of $23 \pm 3^{\circ} \mathrm{C}$ and relative humidity of $70 \pm 10 \%$ throughout the experimental period. All mice were housed in group cages with two animals per cage and were given free access to standard pellets and water. Animal experiments were carried out in strict accordance with the Guide for the Care and Use of Laboratory Animals of the National Institutes of Health and all protocols and studies were approved by the Ethics Committee of Hainan Medical College for Animal Care and Use (Hainan, China). For the care and use of animals utilized in this research, animals were monitored twice a week and none of animals succumbed or exhibited severe illness that would require early euthanasia during the whole experiment. Early sacrifice would have been performed if one of the following criteria were met: Loss of $>20 \%$ body weight, a wound that cannot be improved following medication or the development of neurological symptoms in animals stopping them from being able to feed themselves. For anesthesia and sacrifice, mice were treated with $2-3 \%$ isoflurane inhalation and $3 \% \mathrm{CO}_{2}$ inhalation, respectively.

Preparation of the plant extract. The ripe fruit of A. oxyphylla were purchased from a market specializing in herbs (Herb Market, Haikou, China) in February 2014. The plant was authenticated by Dr Qiang Liu of the Department of Pharmacognosy, Hainan Medical college (Haikou, China). A. oxyphylla was extracted with $640 \mathrm{ml}$ water for $16 \mathrm{~h}$ at $90^{\circ} \mathrm{C}$. This process was conducted twice. The plant extract was then lyophilized and stored at room temperature until use in experiments I and II. The dry yield was $8 \%(w / w)$.

2,2-diphenyl-1-picrylhydrazyl (DPPH) assay. The ability of the prepared extracts to scavenge the DPPH radicals was determined by the method described by Wang et al (17). Briefly,
$10 \mu \mathrm{l} \mathrm{AOE}$ of the aforementioned different concentrations was added to $290 \mu \mathrm{l}$ methanol solution of DPPH $(0.1 \mathrm{mM})$. The solution was mixed well and then left at room temperature for $30 \mathrm{~min}$ in the dark. The absorbance of the resulting solution was read at $519 \mathrm{~nm}$ using an Eon $^{\mathrm{TM}}$ Microplate spectrophotometer (Biotek Instruments, Inc., Winooski, VT, USA). Ascorbic acid was employed as a reference and the radical scavenging activity was calculated as a percentage: of DPPH discoloration using the following equation.

$$
\text { DPPH radical scavenging }(\%)=\frac{A_{\text {control }}-A_{\text {sample }}}{A_{\text {control }} \times 100 \%}
$$

where $A_{\text {sample }}$ is the absorbance of the solution when the extract/reference has been added at a particular level and $A_{\text {control }}$ is the absorbance of the DPPH solution without the extract added. All analyses were run in triplicate. The $\mathrm{IC}_{50}$ values calculated denote the concentration of a sample required to decrease the absorbance at $519 \mathrm{~nm}$ by $50 \%$.

Experiment I. A total of 30 mice that purchased from MARC were divided into five groups with six animals in each group. DB/DB group mice and db-/db- $\mathrm{H}_{2} \mathrm{O}$ group (db-/db- mice) were administered placebo (saline) only, while groups db-/db-AOE100, db-/db-AOE300, and db-/db-AOE500 were administered 100, 300 and $500 \mathrm{mg} / \mathrm{kg}$ AOE, respectively, via the intragastric route, once a day for 8 weeks $(\sim 0.2 \mathrm{ml}$ in volume). The effect of AOE on $\mathrm{db}-/ \mathrm{db}$ - mice was determined by changes in body weight assessed by weighing once a week, while non-fasting blood glucose concentrations measurements were analyzed from tail blood taken once a week.

Experiment II. Another group of 304 -week-old male mice also purchased from MARC, which included $10 \mathrm{DB} / \mathrm{DB}$ $(12.1 \pm 1.6 \mathrm{~g})$ and $20 \mathrm{db}-/ \mathrm{db}$ - mice $(17.3 \pm 1.8 \mathrm{~g})$. These mice were divided into 3 groups, with 10 animals in each group and were housed in the same conditions as described previously. $\mathrm{DB} / \mathrm{DB}$ mice group and $\mathrm{db}-/ \mathrm{db}-\mathrm{H}_{2} \mathrm{O}$ group were administered placebo (saline) only, whereas the $\mathrm{db}-/ \mathrm{db}-\mathrm{AOE} 500$ group was administered $500 \mathrm{mg} / \mathrm{kg}$ AOE via the intragastric route once a day for 8 weeks ( $\sim 0.2 \mathrm{ml}$ in volume). At the end of the 8 -week period, following fasting overnight, each animal was weighed. Individual mice were placed in metabolic cages to obtain $24 \mathrm{~h}$ urine collections. Then, the animals were sacrificed using $3 \%$ $\mathrm{CO}_{2}$ inhalation, and blood and tissue samples were collected for analysis. Blood samples were collected from the hepatic portal vein into a tube for EDTA anticoagulation and centrifuged $\left(1,000 \times \mathrm{g}\right.$ for $15 \mathrm{~min}$ at $\left.4^{\circ} \mathrm{C}\right)$ to separate the plasma. The plasma was then frozen at $-70^{\circ} \mathrm{C}$ for biochemical analysis. The liver and kidneys were excised, weighed and homogenized in a 3:1 v/w of $0.25 \mathrm{M}$ sucrose, $10 \mathrm{mM}$ HEPES, $1 \mathrm{mM}$ EDTA (pH 7.5) buffer. Samples were homogenized for $30 \mathrm{sec}$ at $6.45 \mathrm{~m} / \mathrm{s}$ in an Omni Bead Ruptor (OMNI International IM, Kennesaw, GA, USA). Protein concentrations in each sample were determined using a Bradford protein assay kit (Tiangen Biotech Co., Ltd., Beijing, China).

Glucose tolerance test. Following 6 weeks AOE administration, the blood glucose concentration of mice in experiment II was measured by the oral glucose tolerance test (OGTT). Blood 
samples were collected via the tail vein after an overnight fast and measured for fasting blood glucose concentration. The animals were then administered glucose $(1.0 \mathrm{~g} / \mathrm{kg})$ solution orally. After $2 \mathrm{~h}$, blood samples were again collected via the tail vein and measured to determine $2 \mathrm{~h}$ postprandial blood glucose concentration.

Measurement of plasma concentration levels of glucose, triglycerides and total cholesterol. Commercial kits for glucose (F006), triglycerides (F001-1) and cholesterol (F002-1) were all purchased from the Nanjing Jiancheng Bioengineering Institute (Nanjing, China) and used to measure all parameters, according to the manufacturer's instructions. Glucose concentration was assayed by the glucose oxidase method (18) and total cholesterol and triglyceride levels in plasma were tested using the enzymatic colorimetric method $(19,20)$.

Measurement of hepatic concentrations of reduced glutathione (GSH), malondialdehyde (MDA), peroxidase $(P O D)$ and superoxide dismutase (SOD). These parameters were measured using Commercial kits for GSH (A006-2), MDA (A003-1), POD (A084-3) and SOD (A001-1) were all purchased from the Nanjing Jiancheng Bioengineering Institute (Nanjing, China) and used to measure all parameters, according to the manufacturer's instructions. GSH concentration was assayed using a chromogenic assay. Briefly, $0.5 \mathrm{ml}$ cold EDTA tissue homogenate $(0.02 \mathrm{~mol} / \mathrm{l})$ was added to $0.2 \mathrm{~mol} / \mathrm{l}$ Tris buffer $(\mathrm{pH} 8.2)$ and $0.1 \mathrm{ml}$ 5,5'-dithiobis-(2-nitrobenzoic acid). Samples were centrifuged at $1,350 \times \mathrm{g}$ for $10 \mathrm{~min}$ at room temperature. The absorbance of the clear supernatant was measured at $412 \mathrm{~nm}$ using a Eon ${ }^{\mathrm{TM}}$ Microplate spectrophotometer (Biotek Instruments, Inc.). MDA concentration was assayed using a chromogenic assay. This assay measures free and protein-bound MDA without undue interference from the other lipid peroxidation products (21). The standard curves for the $0-20 \mu \mathrm{mol} / 1$ range were prepared for each assay using the chromogen supplied in the kits. POD was measured by monitoring oxidation of $16 \mathrm{mM}$ guaiacol in $50 \mathrm{mM}$ potassium phosphate buffer ( $\mathrm{pH}$ 6.5), following addition of $10 \mu \mathrm{l}$ $10 \% \mathrm{H}_{2} \mathrm{O}_{2}$ in a $3 \mathrm{ml}$ volume. POD activity was measured as the absorbance increase at $470 \mathrm{~nm}$. SOD activity was measured using the Beauchamp and Fridovich method (22). The total reaction mixture consisting of phosphate buffer (0.5 M, pH 7.4), post-mitochondrial supernatant, xanthine $(1 \mathrm{mM})$ and NBT $(57 \mu \mathrm{M})$ was incubated for $15 \mathrm{~min}$ at room temperature and the reaction was initiated by addition of xanthine oxidase $(50 \mathrm{mU})$. The reaction rate was measured by recording the change in the absorbance at $550 \mathrm{~nm}$.

Measurement of urine concentration of creatinine and BUN. These parameters were measured using Commercial kits for creatinine (C011-2) and BUN (C013-2) were purchased from the Nanjing Jiancheng Bioengineering Institute (Nanjing, China), and used to measure concentrations of creatinine and BUN, according to the manufacturer's instructions. The creatinine concentration was determined by the sarcosine oxidase method (23) and BUN concentration was determined using the Urease method (24).
Urine albumin assay. Urine albumin was measured using an Albumin Mouse ELISA kit (ab108792), which was purchased from Abcam (Cambridge, UK). Absorbance was read using an automated microplate ELISA reader (Biotek Instruments, Inc.) and concentrations were calculated by the standard curve run on each assay plate. All samples were measured in duplicate.

Western blot analysis. Western blot analysis was performed on tissue extracts from the liver and kidney. Antibodies against PTEN (ab32199) and $\beta$-actin (ab129348) were purchased from Abcam. Homogenate $(30 \mu \mathrm{g})$ was separated by $10 \%$ SDS-PAGE and transferred to polyvinylidene difluoride membranes. Membranes were blocked with Thermo Scientific SuperBlock (TBS) Blocking Buffer (cat. no. 37535; Thermo Fisher Scientific, Inc., Waltham, MA, USA) overnight at room temperature. Membranes were then incubated with either anti-PTEN (1:1,000; ab32199, Abcam) or anti- $\beta$-actin $(1: 5,000$; ab129348, Abcam) antibodies for $2 \mathrm{~h}$. Membranes were subsequently incubated with horseradish peroxidase-labeled goat anti-rabbit immunoglobulin G (1;4,000; ab150088, Abcam) for $1.5 \mathrm{~h}$. All membranes were visualized using the Amersham ECL Prime Western Blotting Detection Reagent enhanced chemiluminscence (RPN2232, GE Healthcare Bio-Sciences, Pittsburgh, PA, USA) and exposure to ECL Hyperfilm (GE Healthcare Bio-Sciences). All western blot analyses were performed at least three times.

Statistical analysis. Results are presented as the mean \pm standard deviation. Data were analyzed by the Statistical Product and Service Solutions (SPSS) program ver. 16 (SPSS, Inc., Chicago, IL, USA). Comparisons between two groups were analyzed by Student's $t$-test. $\mathrm{P}<0.05$ was considered to indicate a statistically significant difference.

\section{Results}

Free radical scavenging activity of AOE. The DPPH radical is widely used for the assessment of radical scavenging (25). The soluble free radical DPPH is known to be a good hydrogen abstractor that yields DPPH-H as a by-product (26). The antioxidant activities of $\mathrm{AOE}$ and vitamin $\mathrm{C}$ (a positive control) (15) were measured based on the scavenging activities for a stable DPPH radical as presented in Fig. 1A. On increasing the doses of AOE from $500 \mathrm{mg} / \mathrm{l}$ to $20 \mathrm{~g} / \mathrm{l}$ and that of vitamin $\mathrm{C}$ from 0.5 to $30 \mathrm{mg} / \mathrm{l}$, the values of the DPPH scavenging activity were found to be $1.72 \%(500 \mathrm{mg} / \mathrm{l}), 5.63 \%$ $(1,000 \mathrm{mg} / \mathrm{l}), 12.74 \%$ (2,000 mg/l), 27.63\% (4,000 mg/l), $44.61 \%$ $(6,000 \mathrm{mg} / \mathrm{l}), 64.34 \%(8,000 \mathrm{mg} / \mathrm{l}), 72.35 \%(10,000 \mathrm{mg} / \mathrm{l})$ and $73.75 \%(20,000 \mathrm{mg} / \mathrm{l})$ for AOE and $1.37 \%(0.5 \mathrm{mg} / \mathrm{l}), 8.23 \%$ (1 mg/l), 17.94\% (2 mg/l), 40.62\% (4 mg/l), 69.53\% (8 mg/l), $80.32 \%(15 \mathrm{mg} / \mathrm{l})$ and $90.71 \%$ (30 mg/l) for vitamin C. The half maximal effective concentration $\left(\mathrm{EC}_{50}\right)$ values of $\mathrm{AOE}$ for the scavenging of DPPH radicals were $6,543.2 \mathrm{mg} / \mathrm{l}$ (AOE) and $5.2 \mathrm{mg} / \mathrm{ml}$ (vitamin C). These results suggest that $10 \mathrm{~g} / \mathrm{l} \mathrm{AOE}$ exhibits the optimum antioxidant capacity to scavenge DPPH free radicals.

Effects of AOE on body weight and blood glucose. Changes in body weight in DB/DB and db-/db- mice, and following AOE administration over 8 weeks, did not differ significantly among 
$\mathbf{A}$
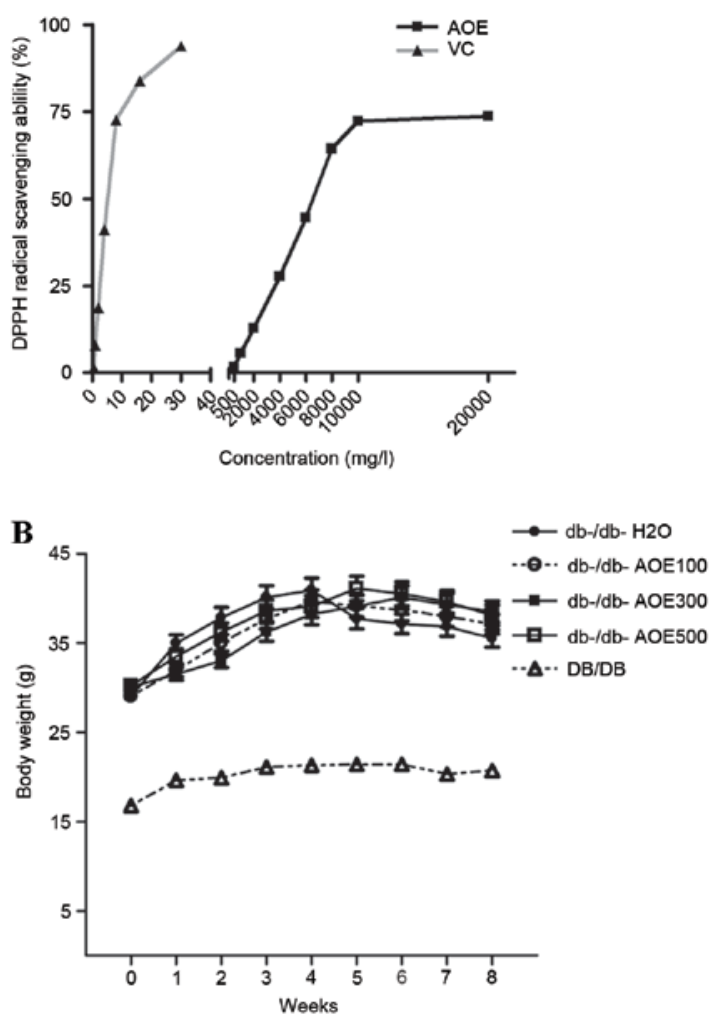

C

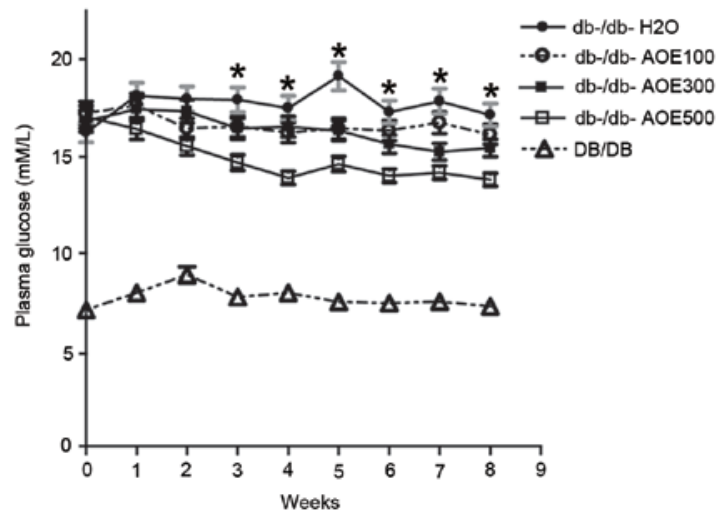

Figure 1. AOE antioxidative capacity and its effect on mice body weight and blood glucose levels. (A) Scavenging activity of different AOE concentrations on the DPPH • radical. Scavenging ability of AOE was compared with that of VC. AOE treatment had little effect on (B) body weight but significantly decreased $(\mathrm{C})$ plasma glucose levels. Data represent the mean \pm standard deviation $(\mathrm{n}=6)$. ${ }^{*} \mathrm{P}<0.05$ for $\mathrm{db}-/ \mathrm{db}-\mathrm{AOE} 500$ treated group compared with $\mathrm{db} / \mathrm{db}-\mathrm{H}_{2} \mathrm{O}$ group. DPPH• radical, 2,2-diphenyl-1-picrylhydrazyl; AOE, Alpinia oxyphylla extract; AOE100, $100 \mathrm{mg} / \mathrm{kg}$ AOE; AOE300, $300 \mathrm{mg} / \mathrm{kg}$ AOE; AOE $500,500 \mathrm{mg} / \mathrm{kg}$ AOE; VC, vitamin C; db-/db- mice, type II diabetic animal model; DB/DB, C57BL/Ks DB/DB mice.

any of the groups (Fig. 1B). Plasma glucose levels decreased significantly $[12 \%(\mathrm{P}<0.05)$ in AOE100, $18 \%(\mathrm{P}<0.05)$ in AOE300 and $28 \%(\mathrm{P}<0.05)$ in AOE500] compared with the $\mathrm{db}-/ \mathrm{db}-\mathrm{H}_{2} \mathrm{O}$ group in a dose-dependent manner (Fig. 1C). The results demonstrated that the highest dose of $\mathrm{AOE}, 500 \mathrm{mg} / \mathrm{kg}$ was most effective in decreasing blood glucose levels.

Effect of AOE on OGTT. OGTTs were performed to determine the effect of a single oral dose of AOE on glucose tolerance in db-/db- mice (Fig. 2A and B). Glucose challenge dramatically increased the blood glucose concentration in db-/db- $\mathrm{H}_{2} \mathrm{O}$
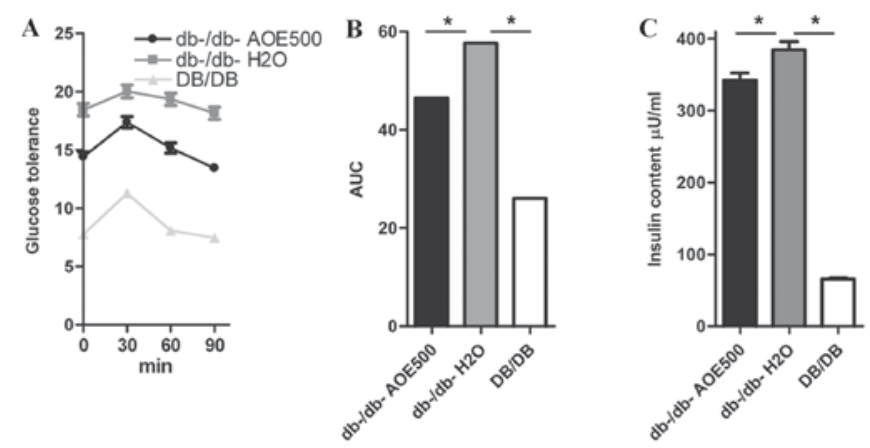

Figure 2. Effect of AOE treatment on glucose tolerance and insulin. (A) Oral glucose tolerance test was performed in $\mathrm{DB} / \mathrm{DB}$ and $\mathrm{db}-/ \mathrm{db}$ - mice treated with control or AOE for 8 weeks. (B) Bar graph shows the AUC of the plot of blood glucose concentration against time. AOE treatment significantly decreased (C) plasma insulin levels. Data represent the mean \pm standard deviation $(\mathrm{n}=10)$. ${ }^{*} \mathrm{P}<0.05$. db-/db- mice, type II diabetic animal model; DB/DB, C57BL/Ks DB/DB mice. AOE, Alpinia oxyphylla extract; AOE500, $500 \mathrm{mg} / \mathrm{kg}$ AOE; AUC, area under the curve.
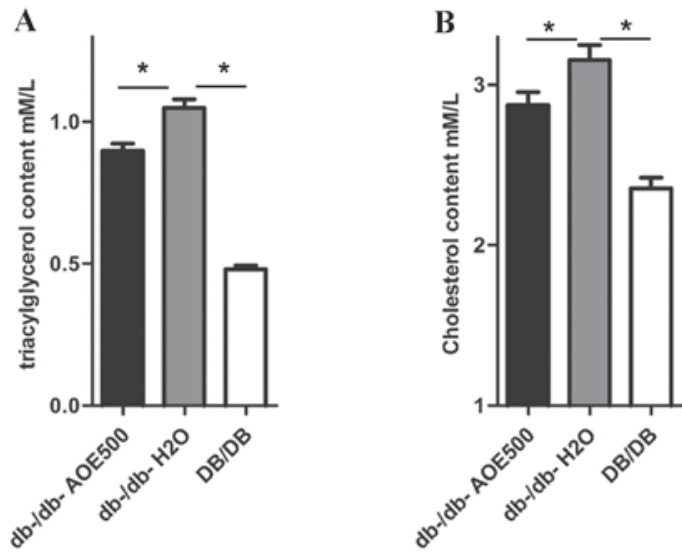

Figure 3. Effect of AOE treatment on lipid levels. AOE treatment significantly decreased (A) plasma triglyceride and (B) plasma total cholesterol levels. Data represent the mean \pm standard deviation $(n=10)$. ${ }^{*} \mathrm{P}<0.05$. AOE, Alpinia oxyphylla extract; AOE500, $500 \mathrm{mg} / \mathrm{kg}$ AOE; db-/db- mice, type II diabetic animal model.

group mice, whereas AOE500 mice exhibited significantly suppressed blood glucose concentration 30,60 and $90 \mathrm{~min}$ following the glucose load (Fig. 2A). When the area under the curve was compared between the groups, that of the $\mathrm{DB} / \mathrm{DB}$ mice was only $39 \%$ of $\mathrm{db}-/ \mathrm{db}-\mathrm{H}_{2} \mathrm{O}$ group $(\mathrm{P}<0.05)$, whereas the AOE500 group showed $19.4 \%$ reduction in blood glucose levels compared with $\mathrm{db}-/ \mathrm{db}-\mathrm{H}_{2} \mathrm{O}$ group $(\mathrm{P}<0.05$; Fig. $2 \mathrm{~B})$.

Effects of AOE on the plasma insulin concentration. The effect of AOE on plasma lipid concentration was studied following AOE administration for 8 weeks in $\mathrm{db}$-/db- mice to reveal the mechanism of the A. oxyphylla effect. The plasma insulin concentration in the $\mathrm{db}-/ \mathrm{db}-\mathrm{H}_{2} \mathrm{O}$ group was found to be significantly higher than in DB/DB mice and db-/db-AOE500 group (both $\mathrm{P}<0.05$; Fig. 2C).

Effects of AOE on dyslipidemia. The effect of AOE500 on plasma lipid concentration revealed significant differences in most of the lipid profiles between the A. oxyphylla-treated and db-/db- $\mathrm{H}_{2} \mathrm{O}$ group mice (Fig. $3 \mathrm{~A}$ and B). The plasma 
A

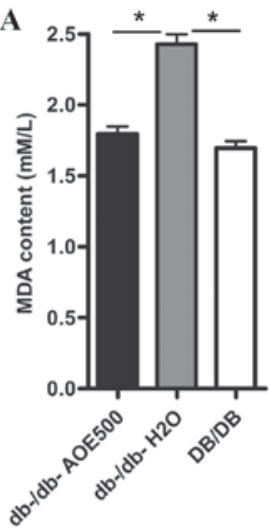

C

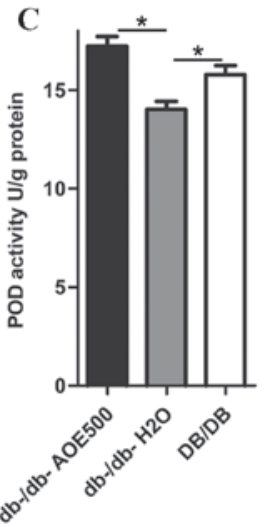

B

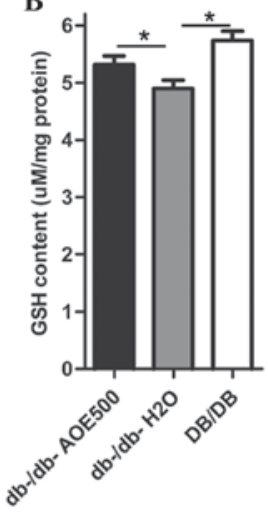

D

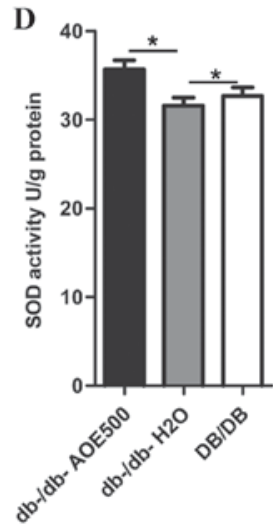

Figure 4. Effect of AOE treatment on oxidative stress. AOE treatment significantly decreased (A) oxidative stress biomarker MDA concentration, increased the (B) antioxidant GSH level and increased the activities of (C) POD and (D) SOD in the liver of $\mathrm{db}-/ \mathrm{db}$ - mice. Data represent the mean \pm standard deviation $(\mathrm{n}=10)$. ${ }^{*} \mathrm{P}<0.05$. AOE, Alpinia oxyphylla extract; db-/db- mice, type II diabetic animal model; AOE, Alpinia oxyphylla extract; AOE500, $500 \mathrm{mg} / \mathrm{kg}$ AOE; MDA, malondialdehyde; SOD, superoxide dismutase; POD, peroxidase.

concentration of triglyceride and cholesterol was significantly increased in $\mathrm{db}-/ \mathrm{db}-\mathrm{H}_{2} \mathrm{O}$ mice compared with $\mathrm{DB} / \mathrm{DB}$ mice. However, the plasma concentrations of triglyceride and cholesterol in the AOE-treated db-/db- mice were $15.0 \%(\mathrm{P}<0.05)$ and $10 \%(\mathrm{P}<0.05)$ lower, respectively, when compared with levels in the $\mathrm{db}-/ \mathrm{db}-\mathrm{H}_{2} \mathrm{O}$ mice.

Effect of AOE on lipid peroxide concentrations and antioxidant enzyme activity. The effects of AOE500 on concentrations of lipid peroxides and activity of antioxidant enzymes in the liver are shown in Fig. 4. The concentration of hepatic thiobarbituric acid reactive substance (TBARS) in the $\mathrm{db}-/ \mathrm{db}-\mathrm{H}_{2} \mathrm{O}$ group was significantly increased compared with that of $\mathrm{DB} / \mathrm{DB}$ mice $(\mathrm{P}<0.05)$. There was a significant decrease in the MDA concentration of AOE500 treated db-/db- mice $(\mathrm{P}<0.05$; Fig. $4 \mathrm{~A})$. As presented in Fig. $4 \mathrm{~B}$, the $\mathrm{GSH}$ content was significantly decreased in $\mathrm{db}-/ \mathrm{db}-\mathrm{H}_{2} \mathrm{O}$ group mice $(\mathrm{P}<0.05)$ and partially recovered following AOE500 treatment $(\mathrm{P}<0.05)$. Activities of superoxide dismutase (SOD) and peroxidase (POD) in the liver of the $\mathrm{db}-/ \mathrm{db}-\mathrm{H}_{2} \mathrm{O}$ group were inhibited compared with those of $\mathrm{DB} / \mathrm{DB}$ group (both $\mathrm{P}<0.05)$. Meanwhile, the activities of SOD and POD in the liver of the AOE500 group were partly restored compared with db-/db- $\mathrm{H}_{2} \mathrm{O}$ group (both $\mathrm{P}<0.05$; Fig. $4 \mathrm{C}$ and $\mathrm{D}$ ).

Effects of $A O E$ on renal function. To assess the effect of $\mathrm{AOE}$ on renal function, urine albumin, creatinine and BUN were measured. The results indicate that urine albumin $(\mathrm{P}<0.05)$, creatinine $(\mathrm{P}<0.05)$ and BUN $(\mathrm{P}<0.05)$ were all significantly increased in $\mathrm{db}-/ \mathrm{db}-\mathrm{H}_{2} \mathrm{O}$ group mice compared with $\mathrm{DB} / \mathrm{DB}$ mice (Fig. 5). Urine albumin excretion was $0.62 \pm 0.17 \mathrm{mg} / 24 \mathrm{~h}$ in AOE500 mice, significantly lower than that of the $\mathrm{db}-/ \mathrm{db}-\mathrm{H}_{2} \mathrm{O}$ group mice $(1.27 \pm 0.31 \mathrm{mg} / 24 \mathrm{~h}, \mathrm{P}<0.05$; Fig. $5 \mathrm{~A})$, although still higher than that of DB/DB group $(0.32 \pm 0.04 \mathrm{mg} / 24 \mathrm{~h}$, $\mathrm{P}<0.05)$. The concentrations of creatinine and BUN were also significantly reduced following AOE500 treatment $(\mathrm{P}<0.05)$, while the BUN-to-Creatinine ratio was decreased. These results indicate that AOE500 treatment improved renal function (Fig. 5B and C).

Effects of AOE on the PTEN expression. In order to detect whether AOE500 impairs diabetic nephropathy development via downregulation of PTEN, PTEN protein expression was examined by western blot analysis. The present study showed that PTEN protein expression was enhanced both in the liver and renal tissue of $\mathrm{db}-/ \mathrm{db}-\mathrm{H}_{2} \mathrm{O}$ group mice. However, PTEN protein expression was significantly decreased $(\mathrm{P}<0.05)$ following AOE500 treatment in the db-/db- mice (Fig. 6).

\section{Discussion}

A. oxyphylla is rich in eudesmane sesquiterpenes, diterpenes, flavonoids and diarylheptanoids, the components found to possess potent antioxidant properties (27). It has been reported that the extract of $A$. oxyphylla fruit exhibits concentration-dependent antioxidant capacity (17). AOE serves a neuroprotective role by attenuating oxidative stress, including increasing the activity of glutathione peroxidase, decreasing levels of MDA and decreasing the neuronal damage and apoptosis that occur in the frontal cortex and hippocampus in mice $(28,29)$. The active phenolic components yakuchinone $\mathrm{A}$ and yakuchinone B that exist in A. oxyphylla exert antiproliferative activity on mouse skin tumor and HL-60 cells, and have anti-inflammatory and antioxidant capacity in vitro. (30) In addition, yakuchinone A exhibit anti-adipocyte differentiation capacity (31). The diarylheptanoids isolated from the fruits of $A$. oxyphylla have potent antioxidant activities in the DPPH assay (32) and eudesmane sesquiterpenes may inhibit nitric oxide production in lipopolysaccharide-induced and interferon-gamma-induced murine macrophages $(14,33)$. Furthermore, protocatechuic acid from A. oxyphylla may protect against hydrogen peroxide-induced oxidative pheochromocytoma cell death (34). In the present study, the ability of the prepared extract of A. oxyphylla to scavenge DPPH radicals was determined. The tested $\mathrm{AOE}$ showed a promising effect on DPPH scavenging in a concentration-dependent manner. Compared with the extracts, ascorbic acid showed higher radical scavenging ability with $37.3 \mathrm{mg} / \mathrm{ml} \mathrm{IC}{ }_{50}$. Although ethanol extracts are reported to have the highest DPPH radical scavenging effect (35), the most common edible form of A. oxyphylla is the boiled form. Thus, the present study tested the anti-diabetic effect of the liquid extract of A. oxyphylla.

Previous studies have shown that hyperglycemia causes oxidative stress, and ROS overproduction serves a role in 

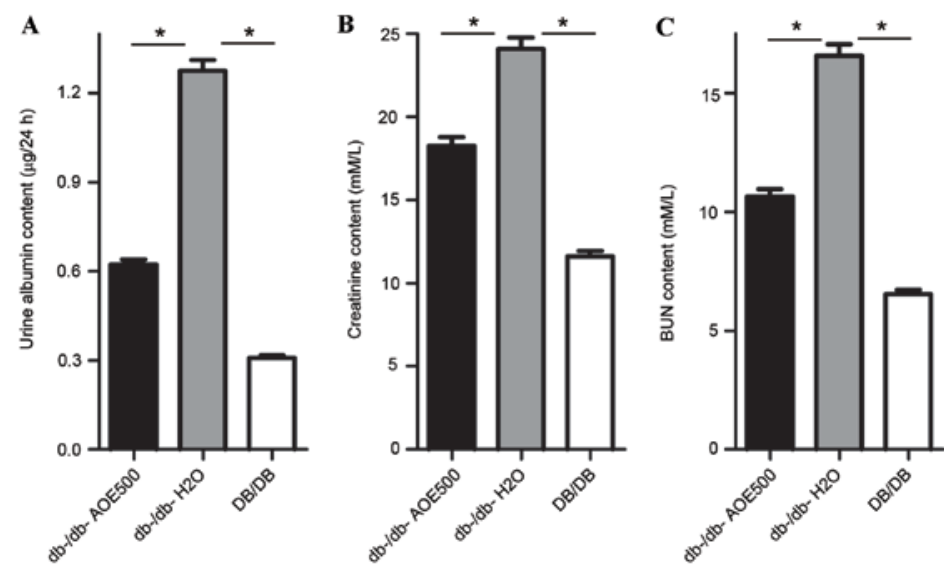

Figure 5. Effect of AOE on renal function. AOE not only significantly decreased the level of (A) urine albumin excretion but also inhibited the decreased levels of (B) urea Creatinine and (C) BUN in comparison with db-/db- $\mathrm{H}_{2} \mathrm{O}$ group mice. Data represent the mean \pm standard deviation $(\mathrm{n}=10)$. ${ }^{*} \mathrm{P}<0.05$. BUN, blood urea nitrogen; AOE, Alpinia oxyphylla extract; AOE500, $500 \mathrm{mg} / \mathrm{kg} \mathrm{AOE}$; db-/db- mice, type II diabetic animal model; DB/DB, C57BL/Ks DB/DB mice.

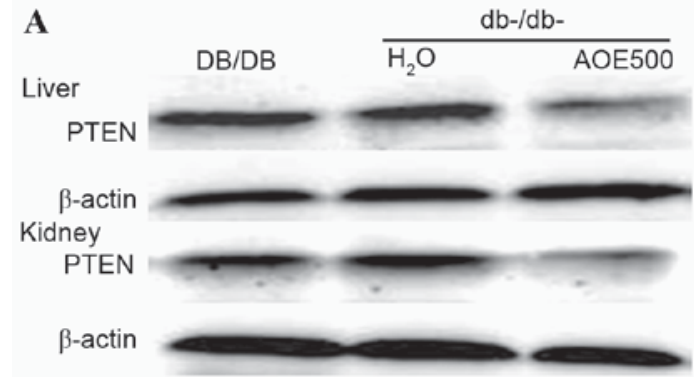

B

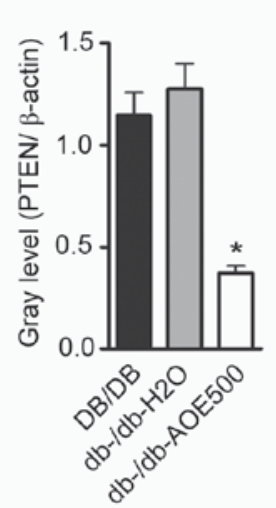

C

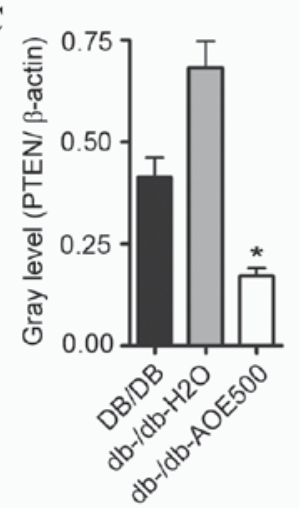

Figure 6. Effect of AOE on PTEN expression. Chronic administration of AOE attenuates high glucose-enhanced PTEN expression in the liver and kidney of $\mathrm{db}$-/db- mice (A). The gray level ratio of PTEN to $\beta$-actin in in the (B) liver and $(\mathrm{C})$ kidney of $\mathrm{db}-/ \mathrm{db}-$ mice. ${ }^{*} \mathrm{P}<0.05$. AOE, Alpinia oxyphylla extract AOE $500,500 \mathrm{mg} / \mathrm{kg}$ AOE; PTEN, Phosphatase and tensin homolog; db-/dbmice, type II diabetic animal model; DB/DB, C57BL/Ks DB/DB mice.

impairing glucose-stimulated insulin secretion and increasing $\beta$-cell apoptosis (36). Under normal circumstances, ROS maintains an optimal oxidative balance for appropriate biological cell function by antioxidants, including GSH, vitamin $\mathrm{C}$ and vitamin $\mathrm{E}$, as well as antioxidant enzymes, such as SOD, POD and catalase. However, in type II diabetes mellitus (T2DM), there are insufficient endogenous antioxidant defenses to balance the increased ROS production. In the present study, db-/db- mice showed decreased GSH concentration, inhibited SOD and POD activities and enhanced MDA levels when compared with the DB/DB mice. In accordance with this finding, Ihara et al (36) reported that the concentration of

protein carbonyls and lipid hydroperoxides increases in the kidneys of db-/db- mice, and that oxidative stress serves an important role in the progression of early diabetic nephropathy. The present study found that AOE-treated db-/db- mice treated with AOE exhibited partially restored antioxidative capacity. Following AOE treatment, the primary non-enzyme antioxidant GSH concentration was significantly higher and antioxidase SOD and POD activity were also increased, whereas lipid peroxidation MDA concentration was decreased in $\mathrm{db}$-/db- mice. AOE anti-oxidative capacity may underlie the beneficial effects of AOE in diabetes.

Previous studies have demonstrated that insulin resistance, the inability of cells to efficiently respond to stimulation by insulin, precedes the onset of T2DM by many years $(37,38)$. In the current study, db-/db- mice exhibited higher insulin concentrations and reduced OGTT compared with DB/DB mice. These results are in accordance with those from previous studies, highlighting that the decreased insulin sensitivity in $\mathrm{db}-/ \mathrm{db}$ - mice results in poor glucose regulation. Following long-term AOE treatment, insulin concentration was significantly decreased and notably, db-/db- AOE500 mice exhibited better OGTT than that of db-/db- $\mathrm{H}_{2} \mathrm{O}$ mice. These results suggest that AOE may mediate db-/db- mice insulin sensitivity to ameliorate the symptoms of diabetes.

At a later stage of T2DM, certain patients develop a progressive increase in the urinary albumin excretion rate, creatinine and BUN, which has been identified as diabetic nephropathy $(39,40)$. The development of renal failure in diabetic nephropathy is due to oxidative stress or inefficient antioxidant systems (41). Oxidative stress may disrupt renal sodium regulation and lead to hypertension (42). The present study demonstrated that $\mathrm{AOE}$ decreased urine albumin excretion and reduced the increase of plasma creatinine and BUN that occurred in $\mathrm{db}-/ \mathrm{db}$ - diabetic mice, indicating that $\mathrm{AOE}$ may protect the kidney glomeruli against diabetic nephropathy.

PTEN overexpression may act as an originator or promoter of diabetic nephropathy. Oxidative stress is one of the activators that regulates the increase of nuclear PTEN expression and additionally inhibits PTEN nuclear export (43). Long-term oxidative stress may induce diabetes by upregulating PTEN expression. Furthermore, the partial knockdown of PTEN 
ameliorates ROS-induced insulin resistance (44). The suppression of PTEN expression produces a marked improvement in blood glucose concentration and insulin sensitivity in diabetic mice (15). Inhibitors of PTEN may therefore serve as target proteins in future drug screens. Interestingly, AOE significantly impaired the PTEN protein level in parallel to the reduced glucose level, and attenuated oxidative stress. Further studies should be conducted to characterize the anti-diabetic component of AOE.

In conclusion, the present study demonstrated that $\mathrm{AOE}$ exhibited significant amelioration in hyperglycemia and hyperlipidemia by reducing blood glucose concentration and oxidative stress, increasing plasma insulin levels, improving renal function and impairing PTEN expression in the type II diabetic C57BL/KsJ db-/db- mice. Therefore, A. oxyphylla may be developed as a novel medicine or functional dietary food supplement to act against diabetes.

\section{Acknowledgements}

The authors wish to thank the Model Animal Research Center of Nanjing University for supplying C3H and G6PDx mice. The present study was funded by the National Natural Science Foundation of China (grant nos. 81473618 and 81360586), the Scientific Research Fund of Hainan Education Department (grant no.HNKY2014-51) and Science Foundation for Fostering Talents of Hainan Medical College (grant no. HY2013-06).

\section{References}

1. Dunkley AJ, Bodicoat DH, Greaves CJ, Russell C, Yates T, Davies MJ and Khunti K: Diabetes prevention in the real world: Effectiveness of pragmatic lifestyle interventions for the prevention of type 2 diabetes and of the impact of adherence to guideline recommendations: A systematic review and Meta-analysis Diabetes Care 37: 922-933, 2014.

2. Liakos A, Karagiannis T, Athanasiadou E, Sarigianni M, Mainou M, Papatheodorou K, Bekiari E and Tsapas A: Efficacy and safety of empagliflozin for type 2 diabetes: A systematic review and meta-analysis. Diabetes Obes Metab 16: 984-993, 2014

3. da Rocha Fernandes J, Ogurtsova K, Linnenkamp U, Guariguata L, Seuring T, Zhang P, Cavan D and Makaroff LE: IDF Diabetes Atlas estimates of 2014 global health expenditures on diabetes. Diabetes Res Clin Pract 117: 48-54, 2016.

4. Nowotny K, Jung T, Hohn A, Weber D and Grune T: Advanced glycation end products and oxidative stress in type 2 diabetes mellitus. Biomolecules 5: 194-222, 2015.

5. Abdali D, Samson SE and Grover AK: How effective are antioxidant supplements in obesity and diabetes? Med Princ Pract 24: 201-215, 2015.

6. Gurzov EN, Tran M, Fernandez-Rojo MA, Merry TL, Zhang X, Xu Y, Fukushima A, Waters MJ, Watt MJ, Andrikopoulos S, et al: Hepatic oxidative stress promotes insulin-STAT-5 signaling and obesity by inactivating protein tyrosine phosphatase N2. Cell Metab 20: 85-102, 2014.

7. Wang X, Zhang W, Chen H, Liao N, Wang Z, Zhang X and Hai C: High selenium impairs hepatic insulin sensitivity through opposite regulation of ROS. Toxicol Lett 224: 16-23, 2014.

8. Evert AB, Boucher JL, Cypress M, Dunbar SA, Franz MJ, Mayer-Davis EJ, Neumiller JJ, Nwankwo R, Verdi CL, Urbanski P and Yancy WS Jr: Nutrition therapy recommendations for the management of adults with diabetes. Diabetes Care 37 (Suppl 1): S120-S143, 2014.

9. Afolayan AJ and Wintola OA: Dietary supplements in the management of hypertension and diabetes-a review. Afr J Tradit Complement Altern Med 11: 248-258, 2014.

10. Patel D, Kumar R, Laloo D and Hemalatha S: Natural medicines from plant source used for therapy of diabetes mellitus: An overview of its pharmacological aspects. Asian Pacific Journal of Tropical Disease 2: 239-250, 2012.
11. Commission CP (ed): Pharmacopoeia of the People's Republic of China, vol.1. China Medical Science and Technology Press, Beijing, 2010.

12. Liu A, Zhao X, Li H, Liu Z, Liu B, Mao X, Guo L, Bi K and Jia Y: 5-Hydroxymethylfurfural, an antioxidant agent from Alpinia oxyphylla Miq. Improves cognitive impairment in $\mathrm{A} \beta_{1-42}$ mouse model of Alzheimer's disease. Int Immunopharmacol 23: 719-725, 2014.

13. Chen J, Wang D and Chen W: Application on Alpinia oxyphylla extraction as food preservative on mango. Food Sci Technol 4: 309-314, 2015 (In Chinese).

14. Qing ZJ, Yong W, Hui LY, Yong LW, Long LH, Ao DJ and Xia PL: Two new natural products from the fruits of Alpinia oxyphylla with inhibitory effects on nitric oxide production in lipopolysaccharide-activated RAW264.7 macrophage cells. Arch Pharm Res 35: 2143-2146, 2012.

15. Butler M, McKay RA, Popoff IJ, Gaarde WA, Witchell D, Murray SF, Dean NM, Bhanot S and Monia BP: Specific inhibition of PTEN expression reverses hyperglycemia in diabetic mice. Diabetes 51: 1028-1034, 2002.

16. Nakashima N, Sharma PM, Imamura T, Bookstein R and Olefsky JM: The tumor suppressor PTEN negatively regulates insulin signaling in 3T3-L1 adipocytes. J Biol Chem 275: 12889-12895, 2000.

17. Wang CZ, Yuan HH, Bao XL and Lan MB: In vitro antioxidant and cytotoxic properties of ethanol extract of Alpinia oxyphylla fruits. Pharm Biol 51: 1419-1425, 2013.

18. Lott JA and Turner K: Evaluation of Trinder's glucose oxidase method for measuring glucose in serum and urine. Clin Chem 21: 1754-1760, 1975 .

19. Fossati P and Prencipe L: Serum triglycerides determined colorimetrically with an enzyme that produces hydrogen peroxide. Clin Chem 28: 2077-2080, 1982.

20. Richmond W: Preparation and properties of a cholesterol oxidase from Nocardia sp. And its application to the enzymatic assay of total cholesterol in serum. Clin Chem 19: 1350-1356, 1973.

21. Janero DR: Malondialdehyde and thiobarbituric acid-reactivity as diagnostic indices of lipid peroxidation and peroxidative tissue injury. Free Radic Biol Med 9: 515-540, 1990.

22. Beauchamp $C$ and Fridovich I: Superoxide dismutase: Improved assays and an assay applicable to acrylamide gels. Anal Biochem 44: 276-287, 1971

23. Fossati P, Prencipe L and Berti G: Enzymic creatinine assay: A new colorimetric method based on hydrogen peroxide measurement. Clin Chem 29: 1494-1496, 1983.

24. Foster LB and Hochholzer JM: A single-reagent manual method for directly determining urea nitrogen in serum. Clin Chem 17: 921-925, 1971.

25. Dinis TC, Maderia VM and Almeida LM: Action of phenolic derivatives (acetaminophen, salicylate, and 5-aminosalicylate) as inhibitors of membrane lipid peroxidation and as peroxyl radical scavengers. Arch Biochem Biophys 315: 161-169, 1994.

26. Du Toit R, Volsteedt Y and Apostolides Z: Comparison of the antioxidant content of fruits, vegetables and teas measured as vitamin C equivalents. Toxicology 166: 63-69, 2001.

27. Miao Q, Kong W, Zhao X, Yang S and Yang M: GC-FID coupled with chemometrics for quantitative and chemical fingerprinting analysis of Alpinia oxyphylla oil. J Pharm Biomed Anal 102: 436-442, 2015.

28. Shi SH, Zhao X, Liu B, Li H, Liu AJ, Wu B, Bi KS and Jia Y: The effects of sesquiterpenes-rich extract of Alpinia oxyphylla Miq. On amyloid- $\beta$-induced cognitive impairment and neuronal abnormalities in the cortex and hippocampus of mice. Oxid Med Cell Longev 2014: 451802, 2014.

29. Shi SH, Zhao X, Liu AJ, Liu B, Li H, Wu B, Bi KS and Jia Y: Protective effect of n-butanol extract from Alpinia oxyphylla on learning and memory impairments. Physiol Behav 139: 13-20, 2015.

30. Surh Y: Molecular mechanisms of chemopreventive effects of selected dietary and medicinal phenolic substances. Mutat Res 428: 305-327, 1999.

31. Lin RJ, Yen CM, Chou TH, Chiang FY, Wang GH, Tseng YP, Wang L, Huang TW, Wang HC, Chan LP, et al: Antioxidant, anti-adipocyte differentiation, antitumor activity and anthelmintic activities against Anisakis simplex and Hymenolepis nana of yakuchinone A from Alpinia oxyphylla. BMC Complement Altern Med 13: 237, 2013.

32. Bian QY, Wang SY, Xu LJ, Chan CO, Mok DK and Chen SB: Two new antioxidant diarylheptanoids from the fruits of Alpinia oxyphylla. J Asian Nat Prod Res 15: 1094-1099, 2013. 
33. Xu J, Ji C, Zhang Y, Su J, Li Y and Tan N: Inhibitory activity of eudesmane sesquiterpenes from Alpinia oxyphylla on production of nitric oxide. Bioorg Med Chem Lett 22: 1660-1663, 2012.

34. Shui Guan, Bao YM, Bo Jiang and An LJ: Protective effect of protocatechuic acid from Alpinia oxyphylla on hydrogen peroxide-induced oxidative PC12 cell death. Eur J Pharmacol 538: 73-79, 2006.

35. Wang CZ, Yuan HH, Bao XL and Lan MB: In vitro antioxidant and cytotoxic properties of ethanol extract of Alpinia oxyphylla fruits. Pharm Biol 51: 1419-1425, 2013.

36. Ihara Y, Toyokuni S, Uchida K, Odaka H, Tanaka T, Ikeda H, Hiai H, Seino Y and Yamada Y: Hyperglycemia causes oxidative stress in pancreatic beta-cells of GK rats, a model of type 2 diabetes. Diabetes 48: 927-932, 1999.

37. Szendroedi J, Phielix E and Roden M: The role of mitochondria in insulin resistance and type 2 diabetes mellitus. Nat Rev Endocrinol 8: 92-103, 2011.

38. Sun M, Huang X, Jiang L, Yan Y, Li B, Zhong W, Chen J, Zhang Y, Wang Z, Li J and Xie M: Characterization of $\beta$-cell function and insulin resistance in overweight Chinese adolescents with normal glucose tolerance. Exp Ther Med 6: 547-551, 2013.

39. Huang B, Wang Z, Park JH, Ryu OH, Choi MK, Lee JY, Kang YH and Lim SS: Anti-diabetic effect of purple corn extract on C57BL/KsJ db-/db- mice. Nutr Res Pract 9: 22-29, 2015.
40. Parving HH, Oxenbøll B, Svendsen PA, Christiansen JS and Andersen AR: Early detection of patients at risk of developing diabetic nephropathy. A longitudinal study ofurinary albumin excretion. Acta Endocrinol (Copenh) 100: 550-555, 1982.

41. Elks CM, Mariappan N, Haque M, Guggilam A, Majid DS and Francis J: Chronic NF-\{kappa\}B blockade reduces cytosolic and mitochondrial oxidative stress and attenuates renal injury and hypertension in SHR. Am J Physiol Renal Physiol 296: F298-F305, 2009.

42. Banday AA and Lokhandwala MF: Transcription factor Nrf2 protects renal dopamine D1 receptor function during oxidative stress. Hypertension 62: 512-517, 2013.

43. Chang CJ, Mulholland DJ, Valamehr B, Mosessian S, Sellers WR and Wu H: PTEN nuclear localization is regulated by oxidative stress and mediates p53-dependent tumor suppression. Mol Cell Biol 28: 3281-3289, 2008

44. Birnbaum Y, Nanhwan MK, Ling S, Perez-Polo JR, Ye Y and Bajaj M: PTEN upregulation may explain the development of insulin resistance and type 2 diabetes with high dose statins. Cardiovasc Drugs Ther 28: 447-457, 2014. 